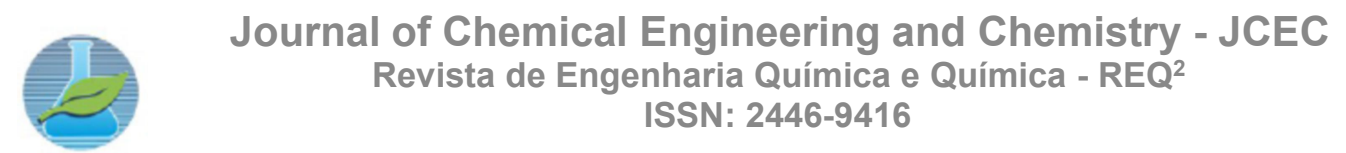

\title{
UMA NOVA PROPOSTA EDITORIAL PARA O PERIÓDICO JCEC/REQ ${ }^{2}$
}

\author{
A. M. O. SIQUEIRA ${ }^{1}$ \\ ${ }^{1}$ Universidade Federal de Viçosa, Departamento de Química \\ Programa de Pós-Graduação em Engenharia Química - PPGEnQ \\ E-mail: antonio.siqueira@ufv.br
}

\section{APRESENTAÇÃO}

A partir desta edição v. 2, n. 3 (2016) o Journal of Chemical Engineering and Chemistry/Revista de Engenharia Química e Química - JCEC/REQ ${ }^{2}$, passará a ser identificado apenas por JCEC/REQ ${ }^{2}$ Journal ou simplesmente, JCEC/REQ ${ }^{2}$, tendo em vista a ampliação das áreas de conhecimento abrangidas pela proposta editorial.

Agora o periódico JCEC/REQ ${ }^{2}$ é um canal de publicação de artigos técnicos científicos da área de Engenharia Química, Engenharia Ambiental, Engenharia de Alimentos, Engenharia de Automação e Controle, Engenharia Mecânica, Engenharia de Produção e demais engenharias e áreas correlatas, de forma a contribuir para o desenvolvimento científico e tecnológico e inovação em Engenharia.

Apesar de se tratar de uma publicação recente, o JCEC/REQ ${ }^{2}$, tem aumentado e qualificado cada vez mais o volume de manuscritos recebidos, bem como o de artigos aceitos para publicação. Trata-se de um sério e árduo trabalho de divulgação do periódico no meio acadêmco-científico, por parte da Equipe Editorial.

Obviamente, assim, como diversos outros periódicos, o JCEC/REQ ${ }^{2}$ tem enfrentado uma série de desafios. Cabe-se destacar a impossibilidade colocada por órgãos de fomento, que exigem como condição primeira para submissão - critério de elegibilidade - de uma proposta de apoio para editoração, que o periódico esteja, obrigatoriamente, indexado nas bases de dados ISI (Thomson Co.), Scopus (da Elsevier), PubMed (US National Library of Medicine) ou Scielo; e estar classificado no mínimo com B2 no Qualis da área ou subárea de conhecimento para o qual esteja se candidatando.

Independentemente, de todas as dificuldades, o JCEC/REQ ${ }^{2}$ vem crescendo, o que mostra que a comunidade científica tem acreditado na proposta., e logo que possível, a indexação nestas bases e classificação, será possível e real.

Assim, nesta edição, com satisfação, são apresentados 14 artigos a comunidade científica, nas áreas de Engenharia de Alimentos, Engenharia Ambiental, Engenharia das Reações Químicas e Catálise, Simulação, Otimização e Controle de Processos, Ensino de Engenharia e Química, Engenharia das Separações e Termodinâmica, Química Analítica, e Fenomenos de Transporte.

O Corpo Editorial do periódico JCEC/REQ ${ }^{2}$ espera que os leitores aproveitem ao máximo o conhecimento publicado nesta edição 


\section{PRESENTATION}

A partir desta edição v. 2, n. 3 (2016) o Journal of Chemical Engineering and Chemistry/Revista de Engenharia Química e Química - JCEC/REQ ${ }^{2}$, passará a ser identificado apenas por JCEC/REQ ${ }^{2}$ Journal ou simplesmente, JCEC/REQ ${ }^{2}$, tendo em vista a ampliação das áreas de conhecimento abrangidas pela proposta editorial.

Agora o periódico JCEC/REQ ${ }^{2}$ é um canal de publicação de artigos técnicos científicos da área de Engenharia Química, Engenharia Ambiental, Engenharia de Alimentos, Engenharia de Automação e Controle, Engenharia Mecânica, Engenharia de Produção e demais engenharias e áreas correlatas, de forma a contribuir para o desenvolvimento científico e tecnológico e inovação em Engenharia.

Apesar de se tratar de uma publicação recente, o JCEC/REQ ${ }^{2}$, tem aumentado e qualificado cada vez mais o volume de manuscritos recebidos, bem como o de artigos aceitos para publicação. Trata-se de um sério e árduo trabalho de divulgação do periódico no meio acadêmco-científico, por parte da Equipe Editorial.

Obviamente, assim, como diversos outros periódicos, o JCEC/REQ ${ }^{2}$ tem enfrentado uma série de desafios. Cabe-se destacar a impossibilidade colocada por órgãos de fomento, que exigem como condição primeira para submissão - critério de elegibilidade - de uma proposta de apoio para editoração, que o periódico esteja, obrigatoriamente, indexado nas bases de dados ISI (Thomson Co.), Scopus (da Elsevier), PubMed (US National Library of Medicine) ou Scielo; e estar classificado no mínimo com B2 no Qualis da área ou subárea de conhecimento para o qual esteja se candidatando.

Independentemente, de todas as dificuldades, o JCEC/REQ ${ }^{2}$ vem crescendo, o que mostra que a comunidade científica tem acreditado na proposta., e logo que possível, a indexação nestas bases e classificação, será possível e real.

Assim, nesta edição, com satisfação, são apresentados 14 artigos a comunidade científica, nas áreas de Engenharia de Alimentos, Engenharia Ambiental, Engenharia das Reações Químicas e Catálise, Simulação, Otimização e Controle de Processos, Ensino de Engenharia e Química, Engenharia das Separações e Termodinâmica, Química Analítica, e Fenomenos de Transporte.

O Corpo Editorial do periódico JCEC/REQ ${ }^{2}$ espera que os leitores aproveitem ao máximo o conhecimento publicado nesta edição 